\title{
Postbloom Fruit Drop of Citrus and Key Lime Anthracnose Are Caused by Distinct Phylogenetic Lineages of Colletotrichum acutatum
}

\author{
N. A. Peres, S. J. MacKenzie, T. L. Peever, and L. W. Timmer
}

First and second authors: University of Florida, Department of Plant Pathology, Gulf Coast Research and Education Center, Wimauma 33598; third author: Washington State University, Department of Plant Pathology, Pullman 99164; and fourth author: University of Florida, Department of Plant Pathology, Citrus Research and Education Center, Lake Alfred 33850.

Accepted for publication 3 November 2007.

\begin{abstract}
Peres, N. A., MacKenzie, S. J., Peever, T. L., and Timmer, L. W. 2008. Postbloom fruit drop of citrus and Key lime anthracnose are caused by distinct phylogenetic lineages of Colletotrichum acutatum. Phytopathology 98:345-352.

Colletotrichum acutatum causes two diseases of citrus, postbloom fruit drop (PFD) and Key lime anthracnose (KLA). PFD is a disease restricted to flowers of sweet orange and most other citrus, and symptoms include petal necrosis, abscission of developing fruit, and the formation of persistent calyces. KLA is a disease of foliage, flowers, and fruits of Key lime only, and symptoms include necrotic lesions on leaves, fruits, twigs, flowers, and blight of entire shoots. The internal transcribed spacers 1 and 2 and the gene encoding the 5.8S ribosomal RNA subunit within the nuclear ribosomal cluster (ITS) and intron 2 of the glyceraldehyde-3-phosphate dehydrogenase gene $(G 3 P D)$ were sequenced for isolates from PFDaffected sweet orange and KLA-affected Key limes collected in the United States (Florida), Brazil (São Paulo), Mexico, Belize, Costa Rica, and the Dominican Republic to determine if there are consistent genetic

from all countries sampled plus a few isolates from flowers of Key lime in Brazil. The other clade (KLA clade) contained KLA isolates from Key lime foliage from all countries sampled and one isolate from flowers of sweet orange in Mexico. In greenhouse inoculations with PFD and KLA isolates from Florida, isolates from both clades produced PFD symptoms on Orlando tangelo flowers, but KLA-clade isolates produced significantly less severe symptoms. PFD-clade isolates were not pathogenic to Key lime foliage, confirming previous studies. The differentiation of PFD and KLA isolates into two well-supported clades and the pathogenicity data indicate that PFD and KLA are caused by distinct phylogenetic lineages of $C$. acutatum that are also biologically distinct. PFD is a recently described disease (first reported in 1979) relative to KLA (first reported in 1912) and it had been proposed that strains causing PFD evolved from strains causing KLA eventually losing pathogenicity to Key lime foliage. We reject the hypothesis that PFD strains have diverged from KLA strains recently based on estimated divergence times of haplotypes and it appears that PFD and KLA strains have been dispersed throughout the Americas independently in association with each host.
\end{abstract} differences between PFD and KLA isolates over the geographic area where these diseases occur. Based on the sequence data, isolates clustered into two well-supported clades with little or no sequence variation among isolates within clades. One clade (PFD clade) contained PFD isolates
Additional keywords: Gloeosporium limetticolum, Colletotrichum gloeosporioides.
Postbloom fruit drop (PFD) is caused by Colletotrichum acutatum J. H. Simmonds $(7,31,32)$. The pathogen infects flower petals causing peach to orange-colored lesions on open flowers and flower buds. Subsequently, the fruitlet abscises leaving the calyx and floral disk attached to the twig. These persistent structures remain attached for the life of the twig, and the leaves around inflorescences are usually twisted and distorted. Fruit abscission and persistent calyxes are related to high levels of indoleacetic acid and other hormones in affected flowers (18). PFD affects most citrus species but is most severe on sweet oranges, lemons, and limes, and less severe on grapefruit and tangerines. PFD was described first in Belize in 1979 (8), although there are informal reports of the disease in Belize, Colombia, and Mexico prior to that date $(25,41)$. In the past 25 years, PFD has appeared in all major, humid citrus production areas of the Americas (39) and severe outbreaks have occurred in Florida (United States) and Brazil. The disease is a limiting factor for citrus production in high rainfall areas of Belize, Mexico, Costa Rica, and the Caribbean islands (38).

Key lime anthracnose (KLA) is also caused by C. acutatum and affects only Key lime, Citrus aurantifolia (Christm.) Swingle

Corresponding author: N. A. Peres; E-mail address: nperes@ufl.edu

doi:10.1094/PHYTO-98-3-0345

(C) 2008 The American Phytopathological Society (synonymous with Mexican, West Indian, and Kagzi limes) (11, 38). This pathogen infects flower petals, leaves, twigs, and fruit, producing necrosis varying from small lesions to blight of entire shoots and inflorescences $(21,22,38)$. The disease does not affect other limes such as Tahiti or Persian limes (C. latifolia Tan.), but these limes are affected by PFD. KLA was described much earlier than PFD (5). It is a serious disease in the major production area of Key limes in semi-arid western Mexico and causes greatly reduced fruit yields following the rainy season $(21,23)$. Key limes are not grown commercially in humid areas of the Americas due to the devastating effects of this disease $(21,23,38)$.

The causal agent of PFD was described originally as Colletotrichum gloeosporioides (Penz.) Penz. \& Sacc. in Penz. (8). Subsequently, this pathogen was re-assigned to $C$. acutatum based on sequencing of the nuclear ribosomal internal transcribed spacer (ITS) region of the genome (4). The causal agent of KLA was described originally as Gloeosporium limetticolum $\mathrm{R}$. E. Clausen (5). When the genus Gloeosporium was revised $(2,34)$, this pathogen was considered to be a form of $C$. gloeosporioides. However, like the PFD pathogen, the KLA pathogen was also reassigned to C. acutatum based on sequences from the ITS region (4).

The pathogens that cause PFD and KLA are difficult to distinguish from one another based on morphological characters (1). PFD and KLA isolates have been characterized genetically in two previous studies $(4,14)$. These studies suggested that, although PFD and KLA isolates are closely related, they are genetically 
distinct. However, only a few isolates from a limited geographic area were included and the putative center of origin of the pathogens was not sampled $(4,14)$. Also, in one of the studies, there was variation among isolates that appeared to overlap between populations (4). In essence, it has been difficult to draw any firm conclusions based on previous genetic studies regarding whether or not $C$. acutatum strains that cause PFD are genetically distinct from those that cause KLA. However, KLA and PFD isolates can be distinguished from one another based on pathogenicity. Pathogenicity assays conducted by Agostini et al. (1) showed that KLA isolates produced all of the symptoms of PFD when sweet orange flowers were inoculated, whereas PFD isolates were only weakly pathogenic to Key lime foliage (1). When the pathogenicity studies were conducted, it was speculated that PFD isolates may have diverged recently from KLA isolates (1). The proposed mechanism by which this occurred was that a KLA strain became established on the flowers of a non-Key lime citrus host and subsequently lost pathogenicity to Key lime foliage. If this hypothesis is correct, PFD isolates from various geographic regions should have lower genetic diversity relative to KLA isolates and represent a genetic subset of the variation observed among KLA isolates.

In the present study, we sampled isolates of $C$. acutatum causing KLA on Key limes, and PFD on sweet orange and other citrus from Belize, Costa Rica, Mexico, Dominican Republic, Florida (United States), and São Paulo (Brazil). The nuclear ribosomal internal transcribed spacer (ITS) and the intron 2 of the glyceraldehyde-3-phosphate dehydrogenase gene were sequenced for each isolate. The pathogenicity of PFD and KLA isolates from Florida to citrus flowers and Key lime foliage was also determined. The objective of this study was to determine if there were consistent genetic differences between KLA and PFD isolates over broad geographic areas and to determine whether or not there was any evidence that the pathogen that causes PFD may have evolved recently from the KLA population. A preliminary report of this study has been published (26).

\section{MATERIALS AND METHODS}

Collection of isolates. All isolates from PFD-affected flowers were collected from sweet orange (Citrus sinensis (L.) Osb.) trees in commercial plantings, except for one isolate from Mexico which was collected from Persian lime flowers. Isolates were chosen from different plantings and multiple locations within countries to maximize geographic diversity of the samples. With the exception of Mexico, where Key lime is grown commercially, KLA isolates were collected from lime anthracnose-affected trees from back yard plantings. All collections were made by the authors between 1999 and 2001 except those from Mexico which were provided by Mario Orozco-Santos (INIFAP, Tecoman, Colima, Mexico). Many of the isolates from Florida and Brazil were from collections made for a previous study (27). A chromogenic isolate from blueberry, described originally by Gunnell and Gubler (15), was collected in North Carolina and a second chromogenic blueberry isolate from Michigan was recovered by the authors from ripe rot-affected fruit purchased in a grocery store. Isolate numbers and the information on the sources are presented in Table 1.

For isolations, affected tissues were surface disinfested by placing them in $95 \%$ ethanol for $30 \mathrm{~s}$, in $1.0 \%$ sodium hypochlorite for $1 \mathrm{~min}$, and rinsing them twice in sterile, distilled water. Small pieces of tissue (approximately $2 \mathrm{~mm}^{2}$ ) were plated on potato dextrose agar (PDA $=4 \mathrm{~g}$ of potato starch, $20 \mathrm{~g}$ of dextrose, and $15 \mathrm{~g}$ of agar per liter) (Difco Laboratories, Sparks, $\mathrm{MD}$ ) and incubated at 23 to $28^{\circ} \mathrm{C}$ for 3 days. Hyphal tips of fungi emerging from tissue pieces were transferred to PDA and grown at $24^{\circ} \mathrm{C}$. Cultures were identified initially by cultural characteristics and conidial morphology. All isolates were single-spored prior to use. Cultures were stored on dry filter papers at $-20^{\circ} \mathrm{C}$ (24).

Pathogenicity tests. Isolates of $C$. acutatum from PFD-affected sweet orange and KLA-affected trees from Florida were grown on PDA for 1 week at $27^{\circ} \mathrm{C}$. Only Florida isolates were used for pathogenicity tests due to quarantine restrictions. Conidia were washed from the dishes, passed through four layers of cheesecloth, and diluted in sterile, distilled water to $10^{6}$ conidia $/ \mathrm{ml}$. Tests for pathogenicity to flowers were conducted using potted 5- to 10-year-old grafted Orlando tangelo (C. reticulata Blanco $\times$ $C$. paradisi Macf.) trees using a method similar to that described by Agostini et al. (1). Flower clusters with buds fully elongated, but not open were chosen for inoculations. Clusters were sprayed to runoff with conidial suspensions, covered with plastic bags for $18 \mathrm{~h}$ and held at 15 to $25^{\circ} \mathrm{C}$ in a greenhouse. Flower clusters were inoculated on seven different dates and on each date all six isolates and a negative water control were used for inoculations. In total, twelve clusters were inoculated per isolate. The number of clusters inoculated on the seven inoculation dates was dependent on availability and ranged from one cluster per isolate to three clusters per isolate. The number of clusters inoculated with each isolate and the water control was the same on each inoculation date to eliminate any systematic bias that the timing of inoculations might introduce. The day after inoculations, the total number of buds for each cluster at any stage of development was counted. The number of open flowers with at least one necrotic lesion and the number of open flowers without any lesions was determined 5 days after inoculation. Thirty days after inoculation, the number of persistent calyxes on each cluster was counted. The number of open flowers with necrosis and the total number of open flowers 5 days postinoculation from the seven inoculation dates were summed and used to calculate the percent of flowers with necrosis. The number of buds counted 1 day post inoculation and the number of persistent calyxes at 30 days postinoculation were also summed over the seven inoculation dates to calculate the percentage of buds that gave rise to persistent calyxes. The percentage of open necrotic flowers relative to the total number of open flowers at day 5 and the percentage of persistent calyxes relative to the total number of buds inoculated for the different isolates or the water control were compared by Fisher's exact test (SAS Institute, Version 9.0, Cary, NC). Differences in the percentage of necrotic flowers or persistent calyxes between groups of isolates categorized as PFD or KLA were assessed using a generalized mixed model. In the model, proportions transformed using the logit link function were described by the fixed effect clade (PFD or KLA) and the random effect isolate nested within the clade. The \% GLIMMIX macro for the SAS software program was used for this analysis and variability of disease incidence for individual isolates was assumed to follow a binomial distribution.

Pathogenicity to Key lime was assessed using 6-month to 1-year-old rooted cuttings, as described by Agostini et al. (1). Two newly emerged shoots on each plant were inoculated with a $10^{6} \mathrm{conidia} / \mathrm{ml}$ spore suspensions of each isolate or sprayed with sterile water. After inoculation, plants were covered with a plastic bag for $18 \mathrm{~h}$ at $24^{\circ} \mathrm{C}$. A visual estimate of the percentage of tissue on the two shoots that was necrotic was made 6 days after inoculation. Inoculations were conducted on four different dates and on each of these dates one plant was inoculated with each isolate or sprayed with a water control. Percentages of leaf necrosis on Key lime caused by the different isolates or the water control were compared using the nonparametric Wilcoxson rank sum test (Statistix, Version 8.1, Analytical Software, Tallahassee, FL).

DNA extraction and sequencing. For production of mycelium for DNA extractions, isolates were grown for 2 days on PDA dishes covered with cellophane at $24^{\circ} \mathrm{C}$. Mycelium was collected from the surface of the cellophane, freeze dried, and ground in liquid nitrogen. Genomic DNA was extracted using the DNeasy kit (Qiagen, Valencia, CA) according to the instructions of the 
manufacturer. DNA concentrations were estimated visually in $0.7 \%$ ethidium bromide-stained agarose gels by comparing band intensity with known quantities of lambda DNA/HindIII markers (Promega, Madison, WI).
The nuclear ribosomal DNA repeat including ITS1, 5.8S rRNA, ITS2, and portions of the genes encoding both small and large subunit rRNAs was amplified using forward primer ITS1 (5'TCCGTAGGTGAACCTGCGG-3') and reverse primer ITS4 (5'-

TABLE 1. Codes and origins of isolates of Colletotricum acutatum used in pathogenicity and sequencing studies

\begin{tabular}{|c|c|c|c|}
\hline Code number & Original name (reference) & Country of origin & Host variety (tissue) \\
\hline BZ-PFD-1 & DLR-A1 & Belize & Sweet orange (flowers) \\
\hline BZ-PFD-2 & MTR-SWO-A1 & Belize & Sweet orange (flowers) \\
\hline BZ-PFD-4 & MDX-SWO-1 & Belize & Sweet orange (flowers) \\
\hline BZ-PFD-7 & BTC-B1 & Belize & Sweet orange (flowers) \\
\hline BZ-PFD-8 & SRV-1 & Belize & Sweet orange (flowers) \\
\hline BZ-PFD-10 & DLR-B1 & Belize & Sweet orange (flowers) \\
\hline BR-PFD-1 & CIT-CA-ITP-20 (27) & São Paulo, Brazil & Sweet orange (flowers) \\
\hline BR-PFD-4 & CIT-CA-ITP-1 (27) & São Paulo, Brazil & Sweet orange (flowers) \\
\hline BR-PFD-7 & SLG-MGG-2 (27) & São Paulo, Brazil & Sweet orange (flowers) \\
\hline BR-PFD-10 & FZR-PRD-2 (27) & São Paulo, Brazil & Sweet orange (flowers) \\
\hline BR-PFD-11 & FSH-CLB-2 (27) & São Paulo, Brazil & Sweet orange (flowers) \\
\hline CR-PFD-1 & Cartago-1 & Costa Rica & Sweet orange (flowers) \\
\hline CR-PFD-4 & Pital-1 & Costa Rica & Sweet orange (flowers) \\
\hline CR-PFD-6 & Los Chiles & Costa Rica & Sweet orange (flowers) \\
\hline CR-PFD-7 & Cachi-1 & Costa Rica & Sweet orange (flowers) \\
\hline CR-PFD-10 & Pocora-4 & Costa Rica & Sweet orange (flowers) \\
\hline DR-PFD-1 & AD F1 C3-1 & Dominican Republic & Sweet orange (flowers) \\
\hline DR-PFD-3 & JJB-1 & Dominican Republic & Sweet orange (flowers) \\
\hline DR-PFD-6 & AD F3 C51-2 & Dominican Republic & Sweet orange (flowers) \\
\hline DR-PFD-7 & AD F4 C70-1 & Dominican Republic & Sweet orange (flowers) \\
\hline DR-PFD-9 & AD F1 C3-3 & Dominican Republic & Sweet orange (flowers) \\
\hline DR-PFD-10 & AD F3 C51-3 & Dominican Republic & Sweet orange (flowers) \\
\hline FL-PFD-1 & RCO-IMK-1 (27) & Florida, USA & Sweet orange (flowers) \\
\hline FL-PFD-3 & OCO-ARC-1 (27) & Florida, USA & Sweet orange (flowers) \\
\hline FL-PFD-5 & VTP-IND-1 (27) & Florida, USA & Sweet orange (flowers) \\
\hline FL-PFD-7 & SGR-FTP-2 (27) & Florida, USA & Sweet orange (flowers) \\
\hline FL-PFD-8 & CLR-IMK-2 (27) & Florida, USA & Sweet orange (flowers) \\
\hline FL-PFD-9 & RCO-IMK-2 (27) & Florida, USA & Sweet orange (flowers) \\
\hline FL-PFD- 14 & OCO-ARC-4 (27) & Florida, USA & Sweet orange (flowers) \\
\hline FL-PFD-15 & ALB-IND-25 (27) & Florida, USA & Sweet orange (flowers) \\
\hline FL- PFD-16 & STF-FTP-10 (27) & Florida, USA & Sweet orange (flowers) \\
\hline MX-PFD-1 & A39NVTab (23) & Tabasco, Mexico & Sweet orange (flowers) \\
\hline MX-PFD-2 & A47NVTam (23) & Tamaulipas, Mexico & Sweet orange (flowers) \\
\hline MX-PFD-7 & A125NVVer (23) & Veracruz, Mexico & Sweet orange (flowers) \\
\hline MX-PFD-8 & A115LPVer (23) & Veracruz, Mexico & Persian lime (flowers) \\
\hline MX-PFD-9 & A40NVTab (23) & Tabasco, Mexico & Sweet orange (flowers) \\
\hline BZ-KLA-1 & PBP-KLA & Belize & Key lime (tissue?) \\
\hline BZ-KLA-2 & MTR-KLA-A1 & Belize & Key lime (tissue?) \\
\hline BZ-KLA-3 & MTR-KLA-B1 & Belize & Key lime (tissue?) \\
\hline BZ-KLA-5 & GVL-1 & Belize & Key lime (leaves) \\
\hline BZ-KLA-6 & ADS & Belize & Key lime (tissue?) \\
\hline BZ-KLA-8 & CREI & Belize & Key lime (flowers) \\
\hline BR-KLA-1 & KLA-MGG-1 & São Paulo, Brazil & Key lime (flowers) \\
\hline BR-KLA-2 & KLA-BTU & São Paulo, Brazil & Key lime (leaves) \\
\hline BR-KLA-4 & KLA-CRD-CV-1 & São Paulo, Brazil & Key lime (leaves) \\
\hline BR-KLA-6 & KLA-MGG-5 & São Paulo, Brazil & Key lime (flowers) \\
\hline BR-KLA-7 & KLA-MGG-7 & São Paulo, Brazil & Key lime (flowers) \\
\hline CR-KLA-1 & Ciudad Colon & Costa Rica & Key lime (leaves) \\
\hline CR-KLA-2 & Rio Frio & Costa Rica & Key lime (leaves) \\
\hline CR-KLA-3 & Aguas Zarca & Costa Rica & Key lime (leaves) \\
\hline CR-KLA-4 & S.F. Palmera & Costa Rica & Key lime (tissue?) \\
\hline CR-KLA-5 & Horquetas & Costa Rica & Key lime (leaves) \\
\hline CR-KLA-6 & Orosi & Costa Rica & Key lime (tissue?) \\
\hline DR-KLA-1 & SBN-1 & Dominican Republic & Key lime (leaves) \\
\hline DR-KLA-2 & SBN-2 & Dominican Republic & Key lime (leaves) \\
\hline DR-KLA-4 & MPL-KLA-2 & Dominican Republic & Key lime (leaves) \\
\hline DR-KLA-5 & RICA & Dominican Republic & Key lime (leaves) \\
\hline DR-KLA-6 & JJB & Dominican Republic & Key lime (tissue?) \\
\hline FL-KLA-1 & GL-PIKE & Florida, USA & Key lime (tissue?) \\
\hline FL-KLA-5 & KLA-Anderson & Florida, USA & Key lime (leaves) \\
\hline FL-KLA-6 & KLA-Jonathan, Hm-1 (4) & Florida, USA & Key lime (tissue?) \\
\hline FL-KLA-7 & Lowes & Florida, USA & Key lime (leaves) \\
\hline FL-KLA-8 & KLA-DPI, Ss (4) & Florida, USA & Key lime (leaves) \\
\hline MX-KLA-1 & A 54 LM Tam (23) & Tamaulipas, Mexico & Key lime (leaves) \\
\hline MX-KLA-3 & A 04 LM Oax (23) & Oaxaca, Mexico & Key lime (leaves) \\
\hline MX-KLA-4 & A 15 LM Col (23) & Colima, Mexico & Key lime (leaves) \\
\hline MX-KLA-5 & A 19 LM Col (23) & Colima, Mexico & Key lime (leaves) \\
\hline MX-KLA-8 & A 50 LM Tam (23) & Tamaulipas, Mexico & Key lime (leaves) \\
\hline MX-KLA-10 & A 06 LM Gro (23) & Guerrero, Mexico & Key lime (leaves) \\
\hline MI-BLU-1 & Mi-BB-2, 04-52 & Michigan, USA & Blueberry (ripe fruit) \\
\hline NC-BLU-1 & Gc-13-1, 96-58 (15) & North Carolina, USA & Blueberry (ripe fruit) \\
\hline
\end{tabular}


TCCTCCGCTTATTGATATGC-3') (44). The region spans bases 1729 to 2310 of a reference nuclear rDNA repeat sequence from C. acutatum (GenBank accession no. AJ301936) (20). The ITS region 1 , the $5.8 \mathrm{~S}$ ribosomal RNA gene, and ITS region 2 were annotated from sequences reported for the small subunit (GenBank accession no. X04971) (33) and 5.8S subunit rRNA (GenBank accession no. M10692) (30) of Neurospora crassa and the large subunit rRNA of Saccharomyces cerevisiae (GenBank accession J01355) (12). Regions flanking the ITS regions of $C$. acutatum and these other species were highly conserved. The complete ITS1, 5.8S rRNA, and ITS2 region was either 494 or $495 \mathrm{bp}$ long for $C$. acutatum isolates in the present study. Intron 2 of the glyceraldehyde 3-phosphate dehydrogenase (G3PD) gene was amplified with the forward primer GDF (5'-GCCGTCAACGACCCCTTCATTGA-3') and reverse primer GDR (5'-GGGTGGAGTCGTACTTGAGCATGT-3') (14). These primers anneal within coding regions of the G3PD gene from nucleotide 1538 to 1817 relative to the G3PD gene of C. gloeosporioides (GenBank accession no. M93427) (36). Intron 2 includes the 216-bp region spanning bases 1574 to 1789 of the reported sequence. For $C$. acutatum isolates in the present study, this region was either 209 or 213 bp long. Amplifications for sequencing used $5 \mathrm{ng}$ of template DNA and were carried out in a $120-\mu$ l volume containing $1 \times$ reaction buffer $(10 \mathrm{mM}$ Tris $[\mathrm{pH} 9], 50 \mathrm{mM} \mathrm{KCl}$, and $2 \mathrm{mM}$ $\mathrm{MgCl}_{2}$ ), $200 \mu \mathrm{M}$ dNTP, 5 units of Taq polymerase, and $60 \rho \mathrm{\rho mol}$ of each primer/reaction. Cycling parameters consisted of a 4-min denaturing step at $94^{\circ} \mathrm{C}$ followed by 34 cycles at $94^{\circ} \mathrm{C}$ for $45 \mathrm{~s}$, $52^{\circ} \mathrm{C}$ (rDNA primers) or $60^{\circ} \mathrm{C}\left(G 3 P D\right.$ primers) for $45 \mathrm{~s}$, and $72^{\circ} \mathrm{C}$ for $1 \mathrm{~min}$. Prior to sequencing, DNA was concentrated to $20 \mathrm{ng} / \mu \mathrm{l}$, using a Microcon YM-30 centrifugal filter (Millipore, Billerica, MA) and 15- $\mu$ l samples were submitted to the University of Florida Interdisciplinary Center for Biotechnology Research in Gainesville. Sequence data were generated from fluorescent cycle sequencing reactions using an automated sequencer (Perkin Elmer/Applied Biosystems, Foster City, CA). Sequence data were generated in forward and reverse directions and alignments were done using CLUSTAL W (37).

Phylogenetic analysis. Sequences from two isolates of $C$. acutatum from blueberry were included in the analysis to identify a node where KLA and PFD clades diverged. The blueberry isolates were chromogenic and belonged to a clade previously shown to form an outgroup from $C$. acutatum isolates from citrus and Key lime based on sequence data from intron regions of the $G 3 P D$ gene and glutamine synthase gene (14). However, the blueberry isolates were not assumed to be an outgroup in our analysis and we report midpoint-rooted trees. An obvious outgroup species would have been $C$. gloeosporioides, but G3PD sequences from KLA and PFD isolates did not align well with sequences from C. gloeosporioides, and therefore sequence data from this species were not included. Maximum parsimony trees and a consensus tree were obtained using PAUP 4.0 (Sinauer Associates, Inc., Sunderland, MA). For the determination of branch lengths, transitions and transversions were weighted equally and gaps treated as a fifth character. An heuristic search employing the tree-bisection-reconnection branch swapping algorithm was used to obtain maximum parsimony trees. Starting trees for branch swapping were constructed by random stepwise-addition. One hundred random addition replicates were performed for each search. Support for nodes of parsimony trees were obtained from 1,000 bootstrapped data sets. Isolates were labeled according to host and site in reported trees. The consensus tree represented the strict consensus of trees constructed from G3PD intron 2 and rDNA sequence data. Bayesian posterior probabilities of sampling nodes were determined with MrBayes 3.1.2 (29). The posterior probabilities are based on maximum likelihood phylogenies assuming the HKY model of sequence evolution for G3PD intron 2 and the F81 model for the rDNA sequence data. Models were selected using the online program FINDMODEL (Los Alamos
National Laboratory, Los Alamos, NM), a web implementation of the program MODELTEST (28). For the tree constructed using combined data, the data were partitioned and both models used to estimate posterior probabilities. Four chains were run for each analysis, one cold and three heated. The temperature parameter was set to 0.2 . Five hundred thousand generations were run and trees sampled every 100 generations. The burn-in period consisted of the first 100,000 generations. A maximum likelihood tree was also constructed in PAUP for each sequence using the same models of sequence evolution described above and both sequences combined assuming the HKY model of evolution. These trees are not reported, as the overall topology and the branch placement of the midpoint root was the same in these trees and reported maximum parsimony trees.

The depth of the node where KLA and PFD isolates diverged in trees constructed using ITS and G3PD sequence data was estimated using the mean path length method (3). Gaps were excluded from this analysis because only substitution rate estimates were available for these regions. A 95\% confidence interval for each mean path length was estimated from 1,000 bootstrapped maximum parsimony trees in PAUP. To test the hypothesis that the PFD population diverged from the KLA population very recently (decades), upper and lower estimates for the mean path length were converted to dates using substitution rates for Eurotiomycete fungi published by Kasuga et al. (17) and the equation for divergence time was: divergence time = mean path length/ length of gene/substitution rate. Reported substitution rates vary depending on the algorithm used to determine them and the estimate of the Eurotiomycetes/Sordariomycetes divergence used as a calibration point. The most recent estimate for the KLA/PFD divergence from ITS sequence data was calculated using the lower mean path length estimate and the fastest substitution rate estimated for the combined ITS1, ITS2, and 5.8S rDNA region $\left(9.76 \times 10^{-9}\right.$ substitutions/site/year). The early divergence estimate was calculated using the high mean path length estimate and the slowest substitution rate $\left(3.3 \times 10^{-10}\right.$ substitutions/site/year). Recent and early boundaries were calculated for the $G 3 P D$ using the same methodology, only the fastest $\left(92.09 \times 10^{-9}\right.$ substitutions/ site/year $)$ and slowest $\left(0.51 \times 10^{-9}\right.$ substitutions/site/year $)$ reported substitution rates for both introns and synonymous sites were used.

Isolate and sequence deposits. From each of three resolved clades a single isolate originating from the United States was deposited in the American Type Culture Collection (Manassas, VA). Original strain designations of deposited isolates with accession numbers in parenthesis are ALB-IND-25 (MYA-4396), Hm-1 (MYA-4397), and Gc-13-1 (MYA-4398). Based on sequence data from intron 2 of the G3PD gene and the ITS1, 5.8S subunit, and ITS2 of the ribosomal DNA repeat combined, there were four distinct haplotypes. Sequence data from one isolate with each haplotype was deposited into GenBank (National Center for Biotechnology Information, Bethesda, MD). Original strain designations with $G 3 P D$ accession numbers in parentheses are ALB-IND-25 (EU168905), MTR-KLA-A1 (EU168906), Hm1 (EU168907), and Gc-13-1 (EU168908). Original strain designations with rDNA accession numbers in parentheses are ALBIND-25 (EU168901), MTR-KLA-A1 (EU168902), Hm-1 (EU168903), and Gc-13-1 (EU168904).

\section{RESULTS}

Pathogenicity tests. PFD isolates from Florida were highly pathogenic to flowers of Orlando tangelo and affected nearly all open flowers 5 days after inoculation (Table 2). KLA isolates were also pathogenic to flowers of Orlando tangelo but caused significantly less disease than PFD isolates $(P<0.001)$. Persistent calyxes typical of PFD were formed following inoculation with both PFD and KLA isolates. Although there were differences in the percent of calyxes produced between isolates, the clade from 
which the isolate was derived (KLA versus PFD) did not account for these differences $(P=0.89)$. PFD isolates produced virtually no necrosis on Key lime leaves, whereas KLA isolates caused necrosis of about 30 to $60 \%$ of the leaf area inoculated (Table 2).

Phylogenetic analysis. The phylogeny estimated using sequence data from the ITS1-5.8S rRNA-ITS2 region was based on eight parsimony informative sites and the phylogeny estimated from $G 3 P D$ sequence data was based on 24 parsimony informative sites. No homoplasy was observed in either phylogeny. In both phylogenies, citrus isolates formed two clades distinct from that of the blueberry isolates (Fig. 1A and B). A strict consensus of the ITS and G3PD phylogenies separated citrus isolates into two clades, indicating that clades identified from either rDNA or $G 3 P D$ sequence data were the same (Fig. 1C). Bootstrap support for both clades was high based on either rDNA or G3PD sequence data alone. However, when sequence data from both regions of the genome was combined, support for clades was much stronger (Fig. 1D). The phylogram constructed using combined sequence data was based on 32 parsimony informative sites and no homoplasy was detected. One clade contained all the PFD isolates except one of five PFD isolates from Mexico (MX-PFD2). This clade also contained three KLA isolates from Brazil: BRKLA-1, BR-KLA-6, and BR-KLA-7. There was no haplotype variation among isolates of this clade for either sequence. The second clade contained all of the KLA isolates from Belize, Costa Rica, Dominican Republic, United States, and Mexico, and two of the five KLA isolates from Brazil. The G3PD intron 2 sequence was identical for all isolates within this group, but there was a single nucleotide substitution within the gene encoding the $5.8 \mathrm{~S}$ rRNA subunit in four of the six isolates from Belize that differed from the others. Between the two clades, there were four nucleotide differences in the 2nd intron of the G3PD gene and four to five nucleotide or insertion/deletion differences in the rDNA repeat. Blueberry sequences for both genes were identical and distinct from sequences for the PFD and KLA isolates. Within the $G 3 P D$ 2nd intron, there were 21 and 23 nucleotide or insertion/ deletion differences between blueberry isolates and isolates from the PFD and KLA clusters. There were four to six nucleotide or insertion/deletion differences between blueberry and citrus isolates within the rDNA repeat (Table 3).

The $95 \%$ confidence interval for the mean path length from the node where the two identified clades diverged was 0.061 to 3.652 substitutions/locus for the rDNA repeat and 0.530 to 3.757 substitutions/locus for the G3PD intron 2 locus. Based on these estimates and published substitution rates for the combined ITS1, ITS2, and 5.8S rDNA region, synonymous sites and introns, the $95 \%$ confidence interval for the divergence of the rDNA haplotype groups is 12,569 to $22,402,159$ years before present and for the divergence of the G3PD haplotype groups 27,552 to $44,628,952$ years before the present.

\section{DISCUSSION}

PFD and KLA isolates sampled throughout the Americas were differentiated into two well-supported phylogenetic lineages. One clade (PFD) contained almost exclusively PFD isolates and the second clade (KLA) almost exclusively KLA isolates. PFD appears to be of recent origin having been first described in Belize in 1979 (8). Agostini et al. (1) suggested that movement of a C. acutatum strain from Key lime might have been responsible for the sudden emergence of the disease. It is obvious from the current study that PFD did not evolve on this timescale. Neither the ITS haplotype nor the G3PD haplotype of PFD-type isolates was observed among isolates from Key lime foliage, which would be expected if the pathogen recently migrated from this host. The confidence intervals for the estimated time that haplotypes diverged were wide, reflecting the uncertainty of estimates. Mean path lengths were based on only a few nucleotide changes and as a result the $95 \%$ confidence interval for their estimations were wide. In the case of the rDNA region, the upper boundary was 60fold greater than the lower boundary. There were also large differences in the estimated substitution rates over the two regions. For example, the fastest estimated rate for introns and synonymous sites was 180-fold greater than the slowest rate. However, even with the large error in divergence time estimates, the probability that the PFD and KLA clades diverged within the last several thousand years is extremely low. Preliminary results from a study examining a larger number of hosts suggest that hybridization events may occur among related $C$. acutatum isolates (S. J. MacKenzie and N. A. Peres, unpublished data). We also sequenced a third region of the genome, $903 \mathrm{bp}$ of the 2nd intron of the glutamine synthase gene used by Guerber et al. (14), from the Florida isolates employed in pathogenicity tests. There were 27 polymorphic nucleotide sites between the PFD and KLA clades for this gene (S. J. MacKenzie and N. A. Peres, unpublished data). This provides additional support that the PFD population is not derived from a recent hybridization event involving the KLA population, although significant sequence differentiation at a greater number of rapidly evolving loci would be required to conclusively rule out that a recent hybridization event did not occur.

There were a few isolates from PFD-affected flowers and Key limes that did not fall into expected clades including a single PFD isolate from Mexico in the KLA clade and three KLA isolates from Brazil in the PFD clade. Based on the pathogenicity data, it would not be surprising to obtain isolates with the ability to cause KLA from necrotic flowers of citrus species other than Key lime. Also, C. acutatum strains that cause PFD have the ability to infect Key lime flowers (S. J. MacKenzie and N. A. Peres, unpublished data) and as a result it would not be surprising to find PFD-type isolates from Key lime flowers. However, one would not expect to

TABLE 2. Pathogenicity of Colletotrichum acutatum isolates from Florida causing postbloom fruit drop (PFD) and Key lime anthracnose (KLA) to flowers of Orlando tangelo and to foliage of Key lime

\begin{tabular}{|c|c|c|c|c|}
\hline \multirow[b]{2}{*}{ Isolates } & \multicolumn{3}{|c|}{ Orlando tangelo } & \multirow{2}{*}{$\frac{\text { Key lime leaves }}{\text { Necrosis }(\%)}$} \\
\hline & Open flowers, total buds & Necrosis $(\%)$ & Persistent calyxes (\%) & \\
\hline \multicolumn{5}{|l|}{ PFD } \\
\hline FL-PFD-15 & $80,155^{x}$ & $100.0 \mathrm{a}^{\mathrm{y}}$ & $6.5 b^{y}$ & $0.0 \mathrm{~b}^{\mathrm{z}}$ \\
\hline FL-PFD-16 & 92,199 & $90.2 \mathrm{~b}$ & $11.6 \mathrm{ab}$ & $0.1 \mathrm{~b}$ \\
\hline \multicolumn{5}{|l|}{ KLA } \\
\hline FL- KLA-6 & 86,187 & $46.5 \mathrm{c}$ & $17.6 \mathrm{a}$ & $60.6 \mathrm{a}$ \\
\hline
\end{tabular}

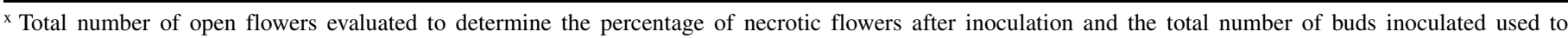
determine the percentage of buds forming persistent calyxes.

y Treatments followed by the same letter had $P>0.05$ in pairwise comparisons using Fisher's exact test.

z Treatments followed by the same letter had $P>0.05$ in pairwise comparisons using the Wilcoxson rank sum test. 


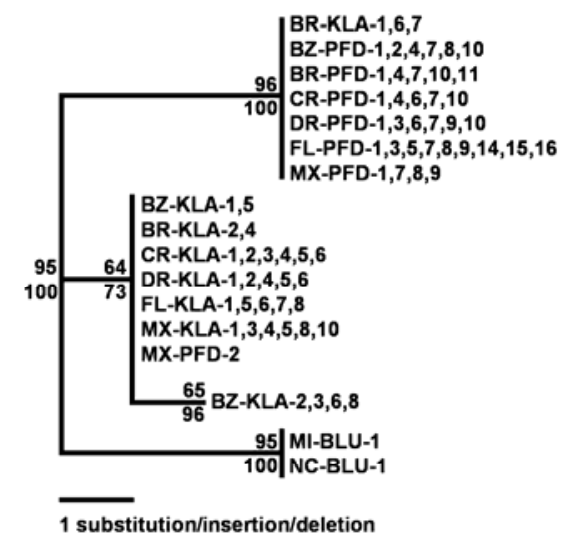

C Strict Consensus

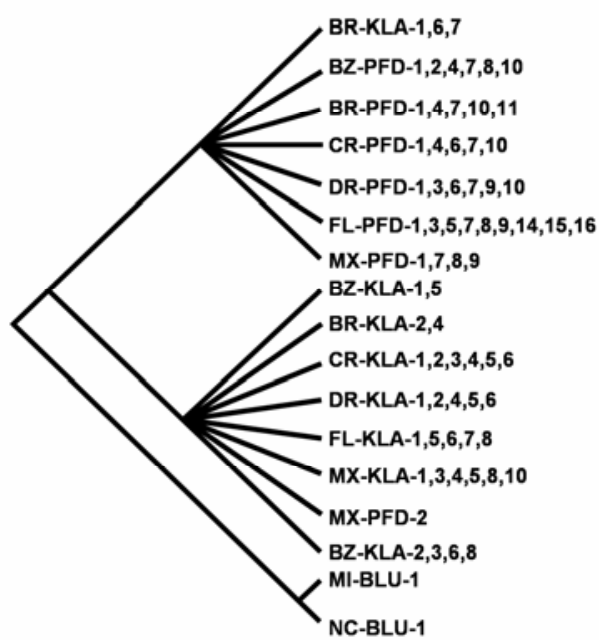

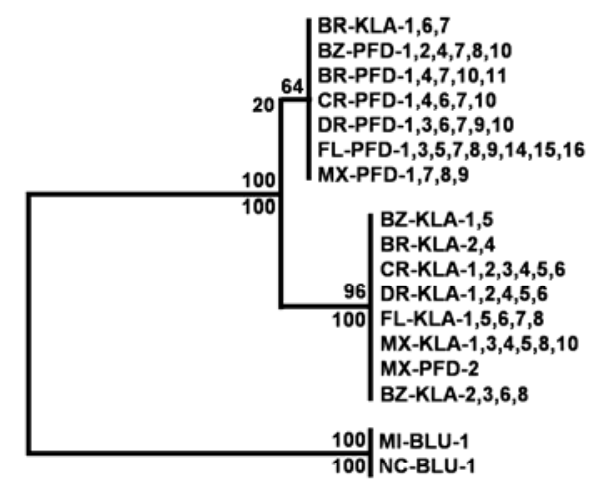

$\overline{1}$ substitution/insertion/deletion

D rRNA (5.8S rRNA, ITS1, ITS2) +

Glyceraldehyde 3-phosphate dehydrogenase 2nd Intron

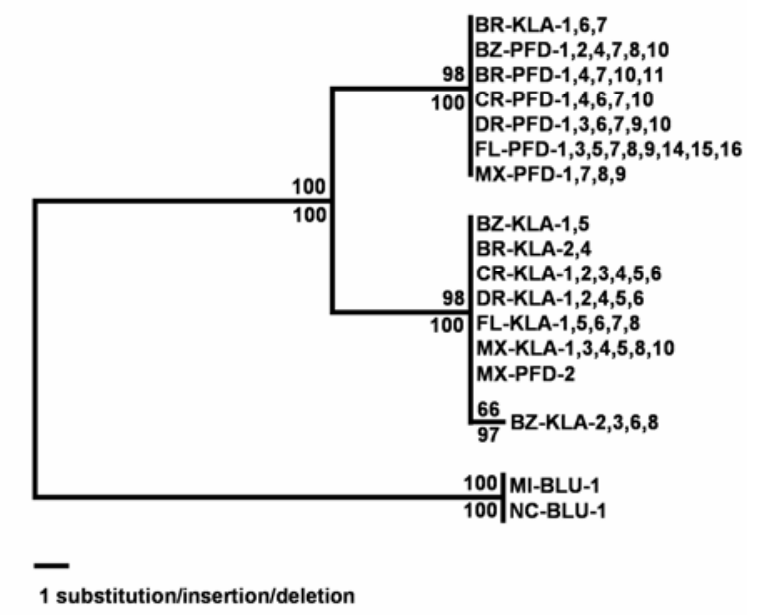

Fig. 1. Maximum parsimony phylograms showing phylogenetic relationships among isolates of Colletotrichum acutatum causing postbloom fruit drop (PFD) and Key lime anthracnose (KLA) from Belize (BZ), São Paulo, Brazil (BR), Costa Rica (CR), Dominican Republic (DR), Florida, USA (FL), and Mexico (MX) based on sequences of A, the ITS1, 5.8s, and ITS2 regions of ribosomal DNA and $\mathbf{B}$, the 2nd intron of the glyceraldehyde-3-phosphate dehydrogenase gene (G3PD). $\mathbf{C}$, Strict consensus phylogeny based on ribosomal DNA sequences and the 2nd intron of G3PD and $\mathbf{D}$, phylogeny based on the combined sequence of both the ribosomal DNA and the G3PD 2nd intron. Numbers above nodes are bootstrap values determined for the maximum parsimony phylogenies (shown) and numbers beneath nodes are Bayesian posterior probabilities for maximum likelihood phylogenies (identical topologies to parsimony trees, not shown).

find PFD-type isolates on Key lime foliage because they fail to produce symptoms on this tissue. The Brazilian KLA isolates that grouped with PFD isolates were recovered from symptomatic flowers (Table 1). Flowers were sampled at the site where these isolates were found because no symptoms were present on Key lime foliage. The Key lime trees at this site were also situated close to a sweet orange grove where PFD was endemic. Based on this history, there is a reasonable probability that these isolates were disseminated from another citrus host. The PFD isolate from Mexico, MX-PFD-2, in the KLA clade, was collected from sweet orange flowers on an experiment station in Ciudad Victoria, Tamaulipas, Mexico, where numerous Key limes with anthracnose were also present. We presume that the MX-PFD-2 isolate represents a KLA isolate from a chance infection of sweet orange flowers. The isolate also grouped with KLA isolates based on random amplified polymorphism DNA (RAPD) analysis, was pathogenic to Key lime foliage, and had appressoria typical of KLA isolates (22). No PFD-type isolates were recovered from Key lime foliage as would be expected based on pathogenicity results. Given that only one KLA-type isolate was obtained from a nonKey lime flower and the site where the isolate was found was in close proximity to a sweet orange grove, it also appears that incursions of KLA-type isolates to sweet orange flowers are not sustainable. PFD isolates can survive between blooms as appressoria on leaf surfaces $(39,40,45)$. Possibly, KLA isolates lack this ability and that may be the reason that they are not isolated more frequently from non-Key lime flowers.

Although it is clear that PFD and KLA isolates are phylogenetically distinct, it is not clear how the pathogens became established and evolved on their citrus hosts or if these lineages can infect hosts other than citrus. PFD and KLA are important diseases of citrus only in the Americas (39). To our knowledge, lime anthracnose has been reported outside of the Americas only in Zanzibar $(42,43)$. Citrus originated in Asia and it is possible that both diseases occur there and simply have not been reported. A survey of citrus species within Asia for PFD and KLA would help ascertain whether PFD and KLA strains were introduced into the Americas on host material or if citrus plants became infected through a host shift from some unknown host or hosts in the New World. C. acutatum is often described as a taxonomic species (or group species) comprised of multiple, genetically isolated populations $(6,10,14,19,25)$ and at least some of these populations can be distinguished from one another based on morphological characteristics that correlate with host range $(9,16,19,31,32)$. 


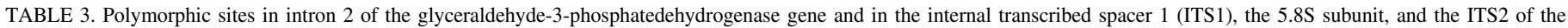
ribosomal DNA repeat for all isolates of Colletotrichum acutatum used in the study

\begin{tabular}{|c|c|c|c|c|c|c|c|c|c|c|c|c|c|c|c|c|c|c|c|c|c|c|c|c|}
\hline \multirow{2}{*}{$\frac{\text { Isolate code no. }}{\text { Consensus site no. }}$} & \multicolumn{24}{|c|}{ Glyceraldehyde-3-phosphate dehydrogenase 2 nd intron } \\
\hline & 15 & 31 & 48 & 51 & 66 & 73 & 80 & 92 & 93 & 98 & 109 & 111 & 113 & 115 & 120 & 136 & 137 & 138 & 150 & 173 & 181 & 183 & 187 & 190 \\
\hline BR-KLA-1,6,7 & . & . & . & . & . & . & . & . & . & . & . & $\mathrm{G}$ & . & . & . & . & . & . & . & . & . & . & . & . \\
\hline BZ-PFD-1,2,4,7,8,10 & . & . & . & . & . & . & . & . & . & . & . & G & . & . & . & . & . & . & . & . & . & . & . & . \\
\hline BR-PFD-1,4,7,10,11 & . & . & . & . & . & . & . & . & . & . & . & G & . & . & . & . & . & . & . & . & . & . & . & . \\
\hline CR-PFD-1,4,6,7,10 & . & . & . & . & . & . & . & . & . & . & . & $\mathrm{G}$ & . & . & . & . & . & . & . & . & . & . & . & . \\
\hline DR-PFD-1,3,6,7,9,10 & . & . & . & . & . & . & . & . & . & . & . & G & . & . & . & . & . & . & . & . & . & . & . & . \\
\hline $\begin{array}{l}\text { FL-PFD-1,3,5,7,8,9,14, } \\
\quad 15,16\end{array}$ & . & . & . & . & . & . & . & . & . & . & . & G & . & . & . & . & . & . & . & . & . & . & . & . \\
\hline MX-PFD-1,7,8,9 & . & . & . & . & . & . & . & . & . & . & . & G & . & . & . & . & . & . & . & . & . & . & . & . \\
\hline BZ-KLA-1,5 & . & . & . & . & . & . & . & . & . & . & . & . & . & . & $\mathrm{G}$ & . & . & . & . & $\mathrm{C}$ & . & . & G & . \\
\hline BZ-KLA-2,3,6,8 & . & . & . & . & . & . & . & . & . & . & . & . & . & . & $\mathrm{G}$ & . & . & . & . & $\mathrm{C}$ & . & . & $\mathrm{G}$ & . \\
\hline BR-KLA-2,4 & . & . & . & . & . & . & . & . & . & . & . & . & . & . & $\mathrm{G}$ & . & . & . & . & $\mathrm{C}$ & . & . & G & . \\
\hline CR-KLA-1,2,3,4,5,6 & . & . & . & . & . & . & . & . & . & . & . & . & . & . & $\mathrm{G}$ & . & . & . & . & $\mathrm{C}$ & . & . & G & . \\
\hline DR-KLA-1,2,4,5,6 & . & . & . & . & . & . & . & . & . & . & . & . & . & . & $\mathrm{G}$ & . & . & . & . & $\mathrm{C}$ & . & . & G & . \\
\hline FL-KLA-1,5,6,7,8 & . & . & . & . & . & . & . & . & . & . & . & . & . & . & G & . & . & . & . & $\mathrm{C}$ & . & . & $\mathrm{G}$ & . \\
\hline MX-KLA-1,3,4,5,8,10 & . & . & . & . & . & . & . & . & . & . & . & . & . & . & $\mathrm{G}$ & . & . & . & . & $\mathrm{C}$ & . & . & $\mathrm{G}$ & . \\
\hline MX-PFD-2 & . & . & . & . & . & . & . & . & . & . & . & . & . & . & G & . & . & . & . & $\mathrm{C}$ & . & . & $\mathrm{G}$ & . \\
\hline MI-BLU-1 & $\mathrm{C}$ & A & $\mathrm{T}$ & A & $\mathrm{A}$ & $\mathrm{A}$ & G & A & G & $\mathrm{T}$ & $\mathrm{C}$ & . & $\mathrm{G}$ & $\mathrm{A}$ & . & $\mathrm{C}$ & G & $\mathrm{T}$ & $\mathrm{T}$ & . & $\mathrm{C}$ & A & . & $\mathrm{T}$ \\
\hline NC-BLU-1 & $\mathrm{C}$ & A & $\mathrm{T}$ & A & A & $\mathrm{A}$ & G & A & G & $\mathrm{T}$ & $\mathrm{C}$ & . & $\mathrm{G}$ & A & . & $\mathrm{C}$ & G & $\mathrm{T}$ & $\mathrm{T}$ & . & $\mathrm{C}$ & A & . & $\mathrm{T}$ \\
\hline Consensus & - & $\mathrm{C}$ & $\mathrm{C}$ & G & G & $\mathrm{C}$ & $\mathrm{C}$ & G & A & C & $\mathrm{T}$ & $\mathrm{T}$ & $\mathrm{T}$ & $\mathrm{C}$ & A & - & - & - & $\mathrm{C}$ & A & G & G & A & $\mathrm{C}$ \\
\hline Isolate code no. & \multicolumn{7}{|c|}{ ITS1 } & \multicolumn{3}{|c|}{$5.8 \mathrm{~S}$} & \multicolumn{14}{|c|}{ ITS2 } \\
\hline Consensus site no. & \multicolumn{4}{|c|}{32} & \multicolumn{3}{|c|}{99} & \multicolumn{5}{|c|}{39} & \multicolumn{3}{|c|}{40} & \multicolumn{3}{|c|}{135} & \multicolumn{3}{|c|}{144} & \multicolumn{3}{|c|}{149} \\
\hline BR-KLA-1,6,7 & \multicolumn{4}{|c|}{ A } & \multicolumn{3}{|c|}{-} & \multicolumn{3}{|c|}{. } & \multicolumn{3}{|c|}{. } & . & & \multicolumn{3}{|c|}{ 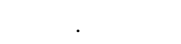 } & & . & & & $\mathrm{T}$ & \\
\hline BZ-PFD-1,2,4,7,8,10 & & & & & & - & & & . & & & & & . & & & . & & & . & & & $\mathrm{T}$ & \\
\hline BR-PFD-1,4,7,10,11 & & & & & & - & & & . & & & & & . & & & . & & & . & & & $\mathrm{T}$ & \\
\hline CR-PFD-1,4,6,7,10 & & & & & & - & & & . & & & & & . & & & . & & & . & & & $\mathrm{T}$ & \\
\hline DR-PFD- $1,3,6,7,9,10$ & & & & & & - & & & . & & & & & . & & & . & & & . & & & $\mathrm{T}$ & \\
\hline $\begin{array}{l}\text { FL-PFD-1,3,5,7,8,9, } \\
\quad 14,15,16\end{array}$ & & & & & & - & & & . & & & & & . & & & . & & & . & & & $\mathrm{T}$ & \\
\hline MX-PFD-1,7,8,9 & & & & & & - & & & . & & & & & . & & & . & & & . & & & $\mathrm{T}$ & \\
\hline BZ-KLA-1,5 & & & & & & . & & & . & & & & & . & & & . & & & $\mathrm{C}$ & & & . & \\
\hline BZ-KLA-2,3,6,8 & & & & & & . & & & $\mathrm{C}$ & & & & & . & & & . & & & $\mathrm{C}$ & & & . & \\
\hline BR-KLA-2,4 & & & & & & . & & & . & & & & & . & & & . & & & $\mathrm{C}$ & & & . & \\
\hline CR-KLA-1,2,3,4,5,6 & & & & & & . & & & . & & & & & . & & & . & & & $\mathrm{C}$ & & & . & \\
\hline DR-KLA-1,2,4,5,6 & & & & & & . & & & . & & & & & . & & & . & & & $\mathrm{C}$ & & & . & \\
\hline FL-KLA-1,5,6,7,8 & & & & & & . & & & . & & & & & . & & & . & & & $\mathrm{C}$ & & & . & \\
\hline MX-KLA-1,3,4,5,8,10 & & & & & & . & & & . & & & & & . & & & . & & & $\mathrm{C}$ & & & . & \\
\hline MX-PFD-2 & & & & & & . & & & . & & & & & . & & & . & & & $\mathrm{C}$ & & & . & \\
\hline MI-BLU-1 & & & & & & . & & & . & & & & & $\mathrm{G}$ & & & $\mathrm{T}$ & & & . & & & . & \\
\hline NC-BLU-1 & & & & & & . & & & . & & & & & $\mathrm{G}$ & & & $\mathrm{T}$ & & & . & & & . & \\
\hline Consensus & & & & & & $\mathrm{C}$ & & & $\mathrm{T}$ & & & & & $\mathrm{C}$ & & & A & & & A & & & $\mathrm{C}$ & \\
\hline
\end{tabular}

Freeman et al. (10) divided $C$. acutatum into four subgroups based on arbitrarily primed PCR, A+T-rich DNA and ITS sequence analysis. Each subgroup contained isolates from diverse hosts such as apple, peach, and pecan, suggesting that genetically similar isolates can have wide host range. No citrus isolates were included in the study. Guerber et al. (14) identified distinct isolate subgroups based on sequence data from two gene introns, mtDNA restriction fragment length polymorphisms (RFLP), intron RFLPs, and mating compatibility. Citrus isolates from New Zealand fell into mt-DNA haplotype F8 and those from sweet orange and Persian lime from Florida were in haplotype $\mathrm{J} 2$, whereas those from Key lime were in haplotype J3. Isolates with J2 and J3 haplotypes were very closely related based on intronic regions of the glutamine synthetase and $G 3 P D$ genes, but were also distinct from one another based on sequences from these genes. Based on this information, the authors recognized that specialization may occur on some hosts such as Key lime. They also concluded that many populations, such as those in their clades $\mathrm{C}$ and $\mathrm{J} 4$, infect a wide range of hosts. Using mitochondrial RFLP analysis, Brown et al. (4) found that citrus isolates could be clearly distinguished from isolates from other hosts such as strawberry, nandina, and chrysanthemum. They also found that four KLA and four PFD isolates from Florida clustered separately from one another based on mitochondrial RFLP patterns. Overall, these studies indicate that there is host specificity within phylogenetic lineages of C. acutatum. However, it is not clear if the host specificity is limited to a single host species or multiple host species. It is very likely that the host specificity of phylogenetic lineages lie on a continuum from very broad host specificity to single-host specificity, but due to the large number of potential hosts and limited time to conduct pathogenicity assays, it is difficult to state where on this continuum a given pathogen occurs.

Taylor et al. (35) proposed that a clonal species should include all individuals that evolved subsequent to the last common ancestor between the clonal population and a recombining population. Apparently, isolates from both clades reproduce only vegetatively because the teleomorph of $C$. acutatum, Glomerella acutata, has never been observed on citrus, and Guerber et al. $(13,14)$ did not report successful crosses involving $\mathrm{J} 2$ and $\mathrm{J} 3$ mitochondrial haplotype isolates. Given that isolates from the KLA and PFD clades are more closely related to one another than they are to a known recombining population (14), at the present time, classifying isolates from the KLA and PFD clades as distinct species does not appear to be warranted based on the above definition of a clonal species.

\section{ACKNOWLEDGMENTS}

We thank S. Williams and W. Usher, from the Citrus Research and Education Institute in Dangriga, Belize, in locating trees affected by these diseases and for the use of facilities for isolations. The assistance of $\mathbf{J}$. Borbón, J. Barceló, and F. Ghurmru in the Dominican Republic, and L. 
Felipe Arauz, E. Arce Coto, and L. Carlos González, from the Universidad de Costa Rica, in locating diseased trees and for the use of their facilities for isolations is also greatly appreciated. We are indebted to M. Orozco-Santos (INIFAP, Tecoman, Colima, Mexico) for providing the isolates from Mexico. We also thank $\mathrm{Z}$. Li for assistance with DNA extractions and C. Moyer for assistance conducting polymerase chain reaction (PCR) amplifications.

\section{LITERATURE CITED}

1. Agostini, J. P., Timmer, L. W., and Mitchell, D. J. 1992. Morphological and pathological characteristics of strains of Colletotrichum gloeosporioides from citrus. Phytopathology 82:1377-1382.

2. Arx, J. A. von. 1970. A revision of the fungi classified as Gloeosporium. Biol. Mycol. 24:1-203.

3. Britton, T., Oxelman, B., Vinnersten, A., and Bremmer, K. 2002. Phylogenetic dating with confidence intervals using the mean path lengths. Mol. Phylogenet. Evol. 24:58-65.

4. Brown, A. E., Sreenivasaprasad, S., and Timmer, L. W. 1996. Molecular characterization of slow-growing orange and key lime anthracnose strains of Colletotrichum from citrus as C. acutatum. Phytopathology 86:523-527.

5. Clausen, R. E. 1912. A new fungus concerned with wither tip of varieties of Citrus medica. Phytopathology 2:217-236.

6. Correll, J. C., Guerber, J. C., Wasilwa, L. A., Sherill, J. F., and Morelock, T. E. 2000. Inter- and intra-species variation in Colletotrichum and mechanisms which affect population structure. Pages 146-179 in: Colletotrichum: Host Specificity, Pathogenicity, and Host-Pathogen Interactions. D. Prusky, S. Freeman, and M. B. Dickman, eds. American Phytopathological Society, St. Paul, MN.

7. Dyko, B. J., and Mordue, J. E. M. 1979. Colletotrichum acutatum. No. 630 in: CMI Descriptions of Pathogenic Fungi and Bacteria. Commonwealth Mycological Institute, Kew, Surrey, England.

8. Fagan, H. J. 1979. Postbloom fruit drop, a new disease of citrus associated with a form of Colletotrichum gloeosporioides. Ann. Appl. Biol. 91:13-20.

9. Freeman, S. 2000. Genetic diversity and host specificity of Colletotrichum species on various fruits. Pages 131-144 in: Colletotrichum: Host Specificity, Pathology, and Host-Pathogen Interactions. D. Prusky, S. Freeman, and M. B. Dickman, eds. American Phytopathological Society, St. Paul, MN

10. Freeman, S., Minz, D., Maymon, M., and Zveibil, A. 2001. Genetic diversity within Colletotrichum acutatum sensu Simmonds. Phytopathology 91:586-592.

11. Fulton, H. R. 1925. Relative susceptibility of citrus varieties to attack by Gloeosporium limetticolum Clausen. J. Agric. Res. 30:629-635.

12. Georgiev, O. I., Nikolaev, N., Hadjiolov, A. A., Skryabin, K. G., Zakharyev, V. M., and Bayev, A. A. 1981. The structure of the yeast ribosomal RNA genes. 4. Complete sequence of the $25 \mathrm{~S}$ rRNA gene from Saccharomyces cerevisiae. Nucleic Acids Res. 9:6953-6958.

13. Guerber, J. C., and Correll, J. C. 2001. Characterization of Glomerella acutata, the teleomorph of Colletotrichum acutatum. Mycologia 93:216229.

14. Guerber, J. C., Liu, B., Correll, J. C., and Johnston, P. R. 2003. Characterization of diversity in Colletotrichum acutatum sensu lato by sequence analysis of two gene introns, mtDNA and intron RFLPs, and mating compatibility. Mycologia 95:872-895.

15. Gunnell, P. S., and Gubler, W. D. 1992. Taxonomy and morphology of Colletotrichum species pathogenic to strawberry. Mycologia 84:157-165

16. Johnston, P. R., and Jones, D. 1997. Relationships among Colletotrichum isolates from fruit-rots assessed using rDNA sequences. Mycologia 89:420-430.

17. Kasuga, T., White, T. J., and Taylor, J. W. 2002. Estimation of nucleotide substitution rates in eurotiomycete fungi. Mol. Biol. Evol. 19:2318-2324.

18. Lahey, K. A., Yuan, R., Burns, J. K., Ueng, P. P., Timmer, L. W., and Chung, K.-R. 2004. Induction of phytohormones and differential gene expression in citrus flowers infected by the fungus Colletotrichum acutatum. Mol. Plant-Microbe Interact. 17:1394-1401.

19. Lardner, R., Johnston, P. R., Plummer, K. M., and Pearson, M. N. 1999. Morphological and molecular analysis of Colletotrichum acutatum sensu lato. Mycol. Res. 103:275-285.

20. Nirenberg, H. I., Feiler, U., and Hagendorn, G. 2002. Description of Colletotrichum lupini comb. nov. in modern terms. Mycologia 94:307320.

21. Orozco-Santos, M. 1995. Enfermedades Presentes y Potenciales de los Citricos en México. Universidad Autonoma, Chapingo, Texcoco, Mexico.

22. Orozco-Santos, M. 2006. Patogenicidad, variabilidad morfológica y genética de Colletotrichum acutatum Simmonds de cítricos en México.
Ph.D. Diss., Universidad de Colima, México.

23. Orozco-Santos, M., Medina-Urrutia, V., Robles-González, M., OrozcoRomero, J., Pérez-Zamora, O., Veláquez-Monreal, J. J., Timmer, L. W., and Guzmán-Gonzáles, S. 2006. Biología y manejo integrado de antracnosis del limón mexicano en el trópico seco de México. INIFAP, Folleto Técnico Núm. 2. Tecomán, Colima, México.

24. Peever, T. L., Canihos, Y., Olsen, L., Ibáñez, A., Liu, Y.-C., and Timmer, L. W. 1999. Population genetic structure and host specificity of Alternaria spp. causing brown spot of Minneola tangelo and rough lemon in Florida. Phytopathology 89:851-860.

25. Peres, N. A., Timmer, L. W., Adaskaveg, J. E., and Correll, J. C. 2005. Life styles of Colletotrichum acutatum. Plant Dis. 89:784-796.

26. Peres, N. A. R., Peever, T. L., Chung, K.-R., and Timmer, L. W. 2003. Molecular characterization of isolates of Colletotrichum acutatum causing postbloom fruit drop of citrus and Key lime anthracnose in the Americas. Page 346 in: Proc. Eighth Congr. Plant Pathol. University of Canterberry, Christchurch, New Zealand.

27. Peres, N. A. R., Souza, N. L., Peever, T. L., and Timmer, L. W. 2004. Benomyl sensitivity of isolates of Colletotrichum acutatum and C. gloeosporioides from citrus. Plant Dis. 88:125-130.

28. Posada, D., and Crandall, K. A. 1998. MODELTEST: Testing the model of DNA substitution. Bioinformatics 14:817-818.

29. Ronquist, F., and Huelsenbeck, J. P. 2003. MrBayes 3: Bayesian phylogenetic inference under mixed models. Bioinformatics 19:15721574.

30. Selker, E., and Yanofsky, C. 1979. Nucleotide sequence and conserved features of the 5.8S rRNA coding region of Neurospora crassa. Nucleic Acids Res. 6:2561-2567.

31. Simmonds, J. H. 1965. A study of the species of Colletotrichum causing ripe fruit rots in Queensland. Queensland Agric. J. 22:437-459.

32. Simmonds, J. H. 1968. Type specimens of Colletotrichum gloeosporioides var. minor and Colletotrichum acutatum. Queensland Agric. J. 25:178A.

33. Sogin, M. L., Miotto, K., and Miller, L. 1986. Primary structure of the Neurospora crassa small subunit ribosomal RNA coding region. Nucleic Acids Res. 14:9540.

34. Sutton, B. C. 1992. The genus Glomerella and its anamorph Colletotrichum. Pages 523-537 in: Colletotrichum: Biology, Pathology, and Control. J. A. Bailey and M. J. Jeger, eds. CAB International, Wallingford, UK.

35. Taylor, J. W., Jacobson, D. J., and Fisher, M. C. 1999. The evolution of asexual fungi: Reproduction, speciation and classification. Annu. Rev. Phytopathol. 37:197-246.

36. Templeton, M. D., Rikkerink, E. H., Solon, S. L., and Crowhurst, R. N. 1992. Cloning and molecular characterization of the glyceraldehyde-3phosphate dehydrogenase-encoding gene and cDNA from the plant pathogenic fungus Glomerella cingulata. Gene 122:225-230.

37. Thompson, J. D., Higgins, D. G., and Gibson, T. J. 1994. CLUSTAL W: Improving the sensitivity of progressive multiple sequence alignment through sequence weighting, position-specific gap penalties and weight matrix choice. Nucleic Acids Res. 22:4673-4680.

38. Timmer, L. W. 2000. Anthracnose diseases. Pages 21-23 in: Compendium of Citrus Diseases. L. W. Timmer, S. M. Garnsey, and J. H. Graham, eds. American Phytopathological Society, St. Paul, MN.

39. Timmer, L. W., Agostini, J. P., Zitko, S. E., and Zulfiqar, M. 1994. Postbloom fruit drop of citrus, an increasingly prevalent disease of citrus in the Americas. Plant Dis. 78:329-334.

40. Timmer, L. W., and Brown, G. E. 2000. Biology and control of anthracnose diseases of citrus. Pages 300-316 in: Host Specificity, Pathology, and Host-Pathogen Interactions of Colletotrichum. D. Prusky, S. Freeman, and M. B. Dickman, eds. American Phytopathological Society, St. Paul, MN.

41. Toledo, C. R. 1970. Principales plagas y enfermedades que atacan a los cultivos más importantes dentro de la jurisdicción de la Junta Regional de Sanidad Vegetal de Martínez de la Torre. Secretaría de Agricultura y Ganadería. Bol. No. 5:1-68.

42. Wheeler, B. E. J. 1963. Withertip disease of limes (Citrus aurantifolia) in Zanzibar. Ann. Appl. Biol. 51:237-251.

43. Wheeler, B. E. J. 1963. Studies on Gloeosporium limetticola causing withertip disease of limes in Zanzibar. Trans. Br. Mycol. Soc. 46:193-200.

44. White, T. J., Bruns, T., Lee, S., and Taylor, J. 1990. Amplification and direct sequencing of fungal ribosomal RNA genes for phylogenetics. Pages 315-322 in: PCR Protocols: A Guide to Methods and Application. M. A. Innis, D. H. Gelfand, J. J. Sninsky, and T. J. White, eds. Academic Press, San Diego, CA.

45. Zulfiqar, M., Brlansky, R. H., and Timmer, L. W. 1996. Infection of flower and vegetative tissues of citrus by Colletotrichum acutatum and $C$. gloeosporioides. Mycologia 88:121-128. 